\title{
Avaliação da Qualidade Microbiológica de Ricota Cremosa Vendida em João Pessoa-PB
}

Eryka Maria Santos Alves (I), Rhayane Idalyne Carvalho (I), Roberta Santos Lima (I), Winnie Alencar Luciano (I), Kataryne Árabe Rimá de Oliveira (I), Jossana Pereira de Sousa (II), Evandro Leite de Souza (I), Maria Lúcia da Conceição (I)

(I) UFPB - Universidade Federal da Paraíba (Cidade Universitária - João Pessoa - PB - Brasil CEP: 58051-900), (II) UFPE - Universidade Federal de Pernambuco (Cidade Universitária -

Recife - PE - CEP: 50670-901)

\section{Resumo}

O queijo ricota é originário da Itália, é suave, não maturado, de sabor levemente ácido e de elevado teor de umidade e nutrientes, o que o faz um ambiente propício à proliferação de micro-organismos. Por isso, objetivouse avaliar a qualidade microbiológica de queijos ricota cremosa, vendidas em João Pessoa-PB. Foram avaliadas 15 amostras de quatro marcas, provenientes de diferentes supermercados, designadas neste estudo como: $\mathrm{QRa}(\mathrm{n}=4), \mathrm{QRb}(\mathrm{n}=3), \mathrm{QRc}(\mathrm{n}=5)$ e $\mathrm{QRd}(\mathrm{n}=3)$. A contagem dos coliformes totais foi realizada pela semeadura (spread plate) de $10 \mu \mathrm{lna}$ superfície do Agar Vermelho Violeta Bile, incubado a $35^{\circ} \mathrm{C}$ por $48 \mathrm{~h}$. As colônias típicas de coliformes totais foram inoculadas em Caldo EC e Agar Eosina Azul de Metileno para confirmação da presença dos coliformes fecais. A pesquisa de Listeria sp. e Salmonella sp. foi desenvolvida considerando-se os métodos convencionais e estrutura morfológica segundo Gram. Os resultados demonstraram que o índice de amostras contaminadas por coliformes foi elevado, tendo-se em vista que os coliformes totais foram identificados em $11(73,33 \%)$ amostras. Na marca QRa os coliformes foram isolados nas quatro amostras avaliadas, com contagens variando entre $1,56 \pm 0,00$ e $6,36 \pm 0,29 \log _{10} \mathrm{UFC} / \mathrm{g}$; na marca $\mathrm{QRb}$ apenas uma das três amostras $\left(5,54 \pm 0,26 \log _{10} \mathrm{UFC} / \mathrm{g}\right)$ estava

\footnotetext{
Referência:

Eryka Maria Santos Alves, Rhayane Idalyne Carvalho, Roberta Santos Lima, Winnie Alencar Luciano, Kataryne Árabe Rimá de Oliveira, Jossana Pereira de Sousa, Evandro Leite de Souza, Maria Lúcia da Conceição. Avaliação da Qualidade Microbiológica de Ricota Cremosa Vendida em João Pessoa-PB. In: Anais do 12 Congresso Latinoamericano de Microbiologia e Higiene de Alimentos - MICROAL 2014 [= Blucher Food Science Proceedings, num.1, vol.1]. São Paulo: Editora Blucher, 2014. DOI 10.5151/foodsci-microal-205
} 
contaminada; em QRc, três das cinco amostras avaliadas apresentaram

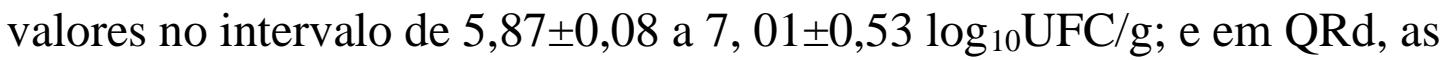
três amostras avaliadas apresentaram contagens entre 5,74 $\pm 0,03 \mathrm{e}$ $6,09 \pm 1,53 \log _{10} \mathrm{UFC} / \mathrm{g}$. Os coliformes fecais foram isolados em quatro $(26,67 \%)$ do total de amostras avaliadas, ressaltando-se que nas marcas QRa e QRd apenas uma amostra de cada foram isolados com contagens de $6,04 \pm 0,00$ e 1,79 $\pm 0,00 \log _{10} \mathrm{UFC} / \mathrm{g}$, respectivamente, e na marca QRc duas amostras com valor igual a $6,2 \log _{10} \mathrm{UFC} / \mathrm{g}$. Das amostras contaminadas com coliformes fecais, três não atendiam a legislação $(2,70 \log \mathrm{UFC} / \mathrm{g})$. Listeria sp. foi identificada em uma amostra das marcas QRb e QRc e em duas da marca QRd, enquanto que Salmonella sp. não isolada em nenhuma das amostras avaliadas. Com esses resultados pode-se afirmar que as contagens das amostras contaminadas por coliformes totais, fecais e Listeria sp. não atendem ao limite máximo permissível pela legislação, realçando a necessidade eminente de verificação das causas dessas contaminações no processo produtivo.

Palavras-Chave: Contaminação, Indicadores de qualidade, Microorganismos, Ricota cremosa

\section{Agência de Fomento:}

